\title{
3 A vida nua e o vida loka: reflexões a partir do pensamento de Giorgio Agamben
}

\section{Tiago Leite ${ }^{1}$}

RESUMo Giorgio Agamben, filósofo e jurista italiano, nascido em 1942 é um dos autores mais lidos atualmente. Iniciou sua produ $\neg$ ção acadêmica nos anos 70 tratando de temas relacionados à esté $\neg$ tica. A partir dos anos 90 volta-se mais objetivamente às questões políticas. A trama conceitual formulada pelo autor e vastíssima, no entanto, para fins desse ensaio, serão abordados os conceitos de estado de exceção, vida nua e campo. Além de discorrer sobre o potencial teórico dessas noções realiza-se uma interface com a ca $\neg$ tegoria nativa vida loka. O objetivo é problematizar em que medida e de que maneira é possível articular a noção de vida nua, proposta por Agamben (2010) à categoria nativa vida loka. Explorando os tencionamentos oriundos dessa articulação, pretende-se verificar a operacionalidade das noções de estado de exceção e campo.

PALAVRAS-CHAVE Estado de Exceção, Vida Nua, Biopolítica, vida loka, Agamben.
ABSTRACT Giorgio Agamben, philosopher and Italian jurist, was born in 1942, is one of the most read authors nowadays. He has initiated his academic production in the 70's, by treating themes related to aesthetics. In the 90's he directs himself more objec tively to political issues. The conceptual weft formulated by the author is extremely wide, therefore, for this issue, there will be tackled the concepts of state of exception, bare life and field. In addition to discourse about the theoretical potential of these notions, we realize an interface with the native category vida loka . The objective is to problematize in what measure and how is possible to articulate the notion of bare life, proposed by Agamben (2010) to native category vida loka. Exploring the intention arising from this articulation, it is intent to verify the operationality notions of state of exception and field.

KEYwORDs State of exception, Bare life, Biopolitic, vida loka, Agamben. 


\section{INTRODUÇÃO}

Giorgio Agamben, filósofo e jurista italiano, nascido em 1942, é um dos autores mais lidos atualmente. Iniciou sua produção acadêmica nos anos 70, tratando de temas relacionados à estética. A partir dos anos 90, volta-se mais objetivamente às questões políticas e lança a obra Homo Sacer: o poder soberano e a vida nua I, publicada em 1995 e traduzida para o português do Brasil somente em 2002. $\mathrm{Na}$ obra, o autor estabelece um encontro entre dois grandes pensadores políticos do século XX: Hanah Arendt e Michel Foucault. É a partir da produção teórica desses dois pensadores que Agamben vai conduzir suas pesquisas e desenvolver uma concepção própria de biopolítica.

A trama conceitual formulada pelo autor é vastíssima, no entanto, para fins desse ensaio, dedico-me às noções de estado de exceção, vida nua e campo. Além de discorrer sobre o potencial teórico dessas noções, pretendo realizar uma interface (ou interelação) com a categoria nativa vida loka. O termo ficou amplamente conhecido quando grupos de Rap passaram a abordá-lo nas letras de suas músicas. Um dos grupos de destaque foi os Racionais MC's, com a faixa Vida loka, gravada no álbum Nada como um dia após o outro, em 2002.

Muitos pesquisadores tem se dedicado à reflexão sobre as reais dimensões da vida loka cantada nos raps. Em pesquisa anterior (LEITE, 2012) realizei uma etnografia das relações sociais estabelecidas por jovens de uma periferia em Paranaguá, onde surgiu com bastante clareza a vida loka como um estilo de vida associado ao "mundo do crime". A pesquisa apontou que, muito mais que realizar efetivamente as "façanhas" narradas, é necessário um conhecimento do conjunto de ações que compõe o estilo vida loka. Malvasi (2012, p. 139) considera a vida loka como uma espécie de dialeto, "a linguagem que delineia um campo semântico comum aos jovens que são da quebrada" um dialeto da vida loka. Nesse sentido, a vida loka pode ser pensada como linguagem que sintetiza as práticas e os valores experimentados por jovens das periferias urbanas, marcadamente associadas a ações e valores ligados a uma mentalidade criminal.

O objetivo é problematizar em que medida e de que maneira é possível articular a noção de vida nua, proposta por Agamben (2010) à categoria nativa vida loka. Explorando os tencionamentos oriundos dessa articulação, pretende-se verificar a operacionalidade das noções de estado exceção e campo enquanto pa- 
radigma biopolítico da modernidade.

\section{RAPAZ É AGREDIDO E ACORRENTADO NU A POSTE NO RIO.}

Com essa manchete, o jornal (versão online) Estadão do dia três de fevereiro de 2014 estampa a matéria especial da seção Notícias. O fato ocorreu na noite do dia 31 de janeiro, no bairro do Flamengo, zona sul do Rio de Janeiro. O jovem foi espancado por um grupo de aproximadamente 15 homens, deixado nu e posteriormente teve seu pescoço atado a um poste com uma corrente de prender bicicletas. A mulher que socorreu o jovem divulgou o caso nas redes sociais e recebeu duras críticas, pois o rapaz espancado seria integrante de uma gangue de assaltantes da zona sul, o que, de certa forma justificaria esse tipo de tratamento. (disponível em http://www. estadao.com.br/noticias/geral,rapaz-e-agredido-e-acorrentado-nu-a-poste-no-rio,1126304,o.htm).

Esse acontecimento desencadeou uma longa lista de debates nas redes sociais, gerando manifestações diversas como, por exemplo, o posicionamento da jornalista Rachel Sheherazade, âncora do jornal SBT Brasil, exibido em horário nobre na televisão aberta:
"O marginalzinho amarrado ao poste era tão inocente que, ao invés de prestar queixa contra seus agressores, preferiu fugir antes que ele mesmo acabasse preso. É que a ficha do sujeito está mais suja do que pau de galinheiro. No país que ostenta incríveis 26 assassinatos a cada 100 mil habitantes, que arquiva mais de $80 \%$ de inquéritos de homicídio e sofre de violência endêmica, a atitude dos vingadores é até compreensível. O Estado é omisso, a polícia é desmoralizada, a Justiça é falha. O que resta ao cidadão de bem que, ainda por cima, foi desarmado? Se defender, é claro. O contra-ataque aos bandidos é o que chamo de legítima defesa coletiva de uma sociedade sem Estado contra um estado de violência sem limite. $\mathrm{E}$, aos defensores dos Direitos Humanos, que se apiedaram do marginalzinho preso ao poste, eu lanço uma campanha: faça um favor ao Brasil, adote um bandido". (disponível em http://oglobo.globo.com/ cultura/revista-da-tv/sbt-comentario-polemico-de-rachel-sheherazade-de-responsabilidade-dela-11524549\#ixzz2srT1WzmG

Em uma breve pesquisa realizada na internet, considerando alguns sites de notícias jornalísticas (carta capital, revista fórum, diário24horas, o globo, estadão, folha centrosul), pude observar um grande número de comentários aprovando a posição da jornalista, bem como sugerindo outras atitudes mais extremas em relação a supostos "bandidos": "Se é bandido, pena eu não ter passado com meu pitbull pra deixar ele brincar um pouquinho... Bandido bom é bandido morto!!" (disponível em http://folhacentrosul.com.br/geral/3521/adote-um-bandido-frase- 
-de-rachel-sheherazade-causa-polemica-nas-redes-sociais).

Os desdobramentos desse episódio informaram ainda que o jovem agredido tinha 15 anos e já havia passado pela polícia algumas vezes por pequenos furtos, dentre os quais o furto de uma furadeira, da casa de um vizinho, fato que motivou sua expulsão de casa e da comunidade onde vivia. Perambulava pelas ruas e quando foi encontrado pelos agressores estava caminhando até Copacabana para tomar banho de mar.

A intenção em trazer esse episódio para o texto é instigar a reflexão sobre as dimensões da biopolítica na contemporaneidade. O que se destaca é a crueldade da violência utilizada contra um adolescente pobre, seguido de amplo apoio de parcela da população aos agressores (ao menos entre aqueles que têm acesso à internet e acessam canais de notícias). Uma das possíveis abordagens de análise para esse fato está em considerar a exacerbação da violência e a assunção da vida nua como centro do debate político contemporâneo. Dessa perspectiva a biopolítica torna-se chave para compreender a passagem das sociedades de poder soberano para as sociedades de controle. (FOUCAULT, 2002) Qual estatuto a vida assume considerando os pressupostos da biopolíti- ca? É possível afirmar que existem vidas de maior ou menor valor? Quem vive e quem morre na sociedade de controle? Que papel ocupa a violência no processo de politização da vida? A noção de vida loka pode ser considerada uma manifestação da vida que foi politizada?

\section{DA POLÍTICA À BIOPOLÍTICA}

Antes de abordar diretamente o debate sobre as transformações políticas ocorridas na passagem do mundo antigo para o moderno, amplamente discutidas por Foucault (2002), e problematizadas por Agamben (2010), propomos a retomada de alguns temas oportunos ao debate sobre a modernidade: beleza, limpeza e ordem. De acordo com Mary Douglas (1976), a "civilização" moderna rejeitou a sujeira e associou diretamente as noções de beleza e progresso às de limpeza e ordem, ou seja, tudo que denotasse desordem era considerado atrasado, tudo que fosse considerado sujo era perigoso e deveria ser eliminado.

No entanto, o ato de colocar em ordem, de limpar, é visto como atividade do cotidiano e não pode ser considerado como negativo, uma vez que todas as culturas estabelecem seus padrões de higiene e 
organização. A questão se complexifica quando esse padrão deixa o espaço doméstico ou cotidiano e se estende à qualificação/desqualificação da vida das pessoas. Nesse sentido, tudo aquilo que coloque em risco o padrão estabelecido, que se constitua numa ameaça para a ordem deve ser afastado, eliminado:

Primeiro estão, reconhecidamente, fora de lugar, uma ameaça à boa ordem, e assim, considerados desagradáveis e varridos vigorosamente. Neste estágio têm alguma identidade: podem ser vistos como pedaços indesejáveis de seja lá o que for: cabelo, comida ou embrulho. Este é o estágio em que são perigosos; sua semi-identidade ainda adere-se e a claridade da cena na qual se intrometeram é prejudicada pela sua presença. Mas, um longo processo de pulverização, decomposição e putrefação aguarda qualquer coisa física que tiver sido reconhecida como suja. No fim, qualquer identidade desapareceu. A origem dos vários pedacinhos e partes está perdida e entraram na massa do lixo comum. É desagradável remexer no refugo para recuperar algo, pois isso restaura a identidade. Enquanto a identidade está ausente, o lixo não é perigoso. (Douglas, 1976, p. 194)

Essa valorização exacerbada da ordem e da pureza ajuda a compreender a escalada do uso da violência ocorrida a partir da modernidade. É nesse contexto de compulsão pela ordem e pureza que Foucault (2001) vai desenvolver suas pesquisas. Entre outras coisas,pergunta-se sobre as manifestações e dimensões do poder. Nesse sentido, aponta as transformações ocorridas entre os séculos XVII e XIX, período no qual o poder exercido pela soberania monárquica passa a ser substituído gradativamente pelo poder disciplinar.

Do ponto de vista jurídico, nas sociedades de soberania o poder era exercido pelo rei, ele é quem detinha a decisão de vida e de morte: fazer morrer, deixar viver. Essa matriz do direito que se baseava na figura do soberano, no século XIX, cedeu espaço a um "novo direito" de "fazer viver, deixar morrer" baseado não mais na figura do soberano, mas no corpo dos súditos. Nesse momento é que a vida passa a ser o objeto central da política. A vida deixa de ser um dado reservado ao espaço privado e passa a ser disciplinada pelas instituições modernas: escola, hospitais, presídios, manicômios, que Foucault investiga em Vigiar e Punir.

É importante destacar que a assunção da vida pela política é operada na passagem do poder soberano para o poder disciplinar, entretanto existem algumas diferenças entre poder disciplinar e biopoder, não no sentido de exclusão mútua, mas de uma mecânica diferenciada: na sociedade disciplinar, o poder se manifesta nos corpos dos indivíduos ao passo que o biopoder se manifesta em suas vidas. Enquanto a disciplina gera individualização, o biopoder gera 
massificação. As ações passam a ser direcionadas para a população, e não para indivíduos isolados. As ações orientadas pelo biopoder redundam em processos globais os quais Foucault (2002) exemplifica: controle da taxa de natalidade, políticas de saúde para alcançar longevidade, criação da seguridade social, ou seja, processos de conjunto que envolvem a população. De acordo com POGREBINSCHI:

É, portanto, a cidade e a população que entram em cena no regime do biopoder. E isso é relevante, segundo Foucault, porque nem o poder da soberania, nem o poder disciplinar operavam com essas noções. A cidade e a população passam a ser problemas políticos, problemas da esfera do poder. E esses problemas ou fenômenos também apresentam outras características em si peculiares. Eles são, por exemplo, essencialmente problemas coletivos, de massa, cuja ocorrência se dá sempre em série e nunca de forma isolada ou individualizada. (Pogrebinschi, 2004, p.196)

Há uma mudança de sentido no exercício do poder, que passa de um poder que gerava morte (poder soberano) para um poder que, supostamente, se propõe preservar a vida (biopoder), mas não apenas preservá-la, no sentido de uma vida que vegetativa. A vigilância do poder disciplinar visava garantir o corpo produtivo, ativo, limpo, saudável. Nesse sentido, compreende-se a compulsão pela beleza, pureza e ordem que tomou conta da modernidade. É sob essas ideias que estados democráticos e estados totalitários empreenderam diversas formas de violências contra todos que estivessem fora do padrão. De acordo com Rosa (2007):

Ao contrário do que poderíamos pressupor, quando o Estado passa a estabelecer políticas públicas para cuidar do corpo da população, protegendo e estimulando, purificando e ordenando a vida, tomando a vida como elemento político por excelência, a violência não diminui, mas passa a ser uma violência depuradora: cuidando da vida de alguns e autorizando a morte de outros. Assim, em meio à velocidade, à fragmentação e à perplexidade no mundo contemporâneo, a violência tomou conta do corpo social e político. (ROSA, 2007 p.19)

Compreende-se que o conjunto de dispositivos disciplinadores surgidos na modernidade, bem como a assunção da vida ao patamar de elemento político por excelência, não diminuiu a escalada da violência, pelo contrário, fez com que a guerra fosse instalada tendo o Estado como um de seus promotores.

Biopolítica que estabelece os limites entre as vidas protegidas, ordenadas, padronizadas e as vidas desprotegidas, sujas e desordenadas. Nesse sentido, faz eco o caso do jovem acorrentado pelo pescoço a um poste no Rio de Janeiro. A violência empregada contra ele pode ser interpretada como o resultado de 
um processo de politização da vida, na qual a condição de "bandidos" ou "delinquentes" permite que qualquer pessoa exerça o poder de morte sobre sua vida. Vida que nessas condições foi desnudada de seus direitos políticos. Fato que se evidencia nas diversas manifestações de apoio aos "justiceiros".

É interessante notar que o limite entre vida digna e vida indigna (que Agamben vai chamar vida nua) é muito tênue: não se percebe a situação degradante dos moradores de periferias que não possuem condições mínimas de habitação ou de alimentação; ou ainda a dureza do cotidiano de um jovem morador em bairro violento; ou a sedução que o "mundo do crime" exerce sobre pessoas com poucas alternativas. O fato é que, quando a vida nua cruza o limite e passa a oferecer risco, torna-se necessário fazer viver e proteger (a vida digna) e deixar morrer (a vida nua).

No que se refere ao caso específico do Brasil, a escalada da violência e, particularmente, os homicídios são emblemáticos dessa biopolítica que decide quem vive e quem morre. De acordo com Manso (2012), em pesquisa sobre o crescimento e queda dos homicídios em São Paulo entre 1960 e 2010, a curva dos homicídios entre os anos 80 e 90 sofreu um crescimento na ordem dos $144 \%$. No início dos anos
1980 a taxa era de 18,5 mortos por 100 mil habitantes, saltando para 44,1 mortos por 100 mil habitantes no início dos anos 1990, sendo que ao final da década (1999) os números chegaram a 65,3 mortes. Os dados apresentados pelo autor demonstram que na década de 60 o município de São Paulo registrou 217 homicídios ao passo que em 1999 o número foi de 6.653 casos. Outro dado que impressiona são as 273 chacinas (caso em que morrem três pessoas ou mais no mesmo evento) cometidas entre 1998 e 2000. Uma das possíveis explicações (entre outras apresentadas na tese) para esse crescimento vertiginoso dos homicídios foi a utilização, por parte do Estado, da execução sumária como ferramenta para conter os roubos e crimes contra o patrimônio. Os presos eram retirados de dentro do presídio e assassinados, posteriormente eram "desovados" em áreas afastadas do centro.

Manso (2012) identifica que em 1970, durante o regime militar, com a criação da PM (polícia militar) os números saltaram de apenas duas mortes envolvendo agentes de segurança no ano de 1965 para 59 casos no ano de 1975. A utilização da execução de suspeitos somente aumentou de lá para cá, abrindo espaço para formação de esquadrões da morte e de justiceiros que agiam (matavam) sob proteção 
das forças policiais e contavam com apoio de comerciantes locais. Essa configuração pode ser vista como momento em que o Estado se apropria da vida dos indivíduos, decidindo qual vale mais, eliminando a vida indigna de ser vivida, e protegendo a vida digna. Os dados demonstram isso: em bairros nobres de São Paulo, os índices eram europeus na casa dos 3 mortos por 100 mil habitantes, ao passo que nas periferias como Jardim Angela os números chegavam 100 casos por 100 mil habitantes.

Sob o discurso de manutenção da ordem e combate aos roubos, a Polícia Militar foi criada e se desenvolveu tendo o homicídio como ferramenta de trabalho. Ainda hoje, o recurso ao auto de resistência seguida de morte é utilizado por policiais militares para encobrir casos de execução de suspeitos.

Agamben (2010) inicia seu trajeto teórico dialogando com Foucault (2002) na definição do conceito de biopolítica, pois foi Michel Foucault quem articulou e fundamentou desde os anos 70 o conceito de biopolítica, lançando-o como questão fundamental para o debate político moderno e contemporâneo. No entanto, é importante frisar que Agamben não se constituiu num seguidor de Foucault, mas num grande conhecedor de sua obra. Esse conhecimento influenciou seu pensamento, no entanto suas pers- pectivas teóricas possuem feições próprias.

Existe uma diferença básica entre o conceito de biopolítica para Foucault e para Agamben. O primeiro concebe a biopolítica como fenômeno diretamente ligado ao surgimento dos Estados modernos, à reorganização dos poderes e ao surgimento de saberes técnico-administrativos. O segundo percebe a biopolítica como experiência ontológica, ou seja, uma dimensão intrínseca à experiência política Ocidental. Essa diferença de perspectiva é visível quando Foucault (2002) estabelece o século XVIII como momento em que emerge a experiência da biopolítica, notadamente como experiência distinta do poder soberano, ao passo que Agamben (2010) vai buscar em Aristóteles as origens da biopolítica e encontrar no direito romano antigo a figura do Homo Sacer para fundamentar a articulação entre biopolítica e poder soberano.

Esse conhecimento sobre o conjunto da obra de Michel Foucault permite que Agamben indique um ponto pouco esclarecido em sua teoria: sobre qual seria o ponto de convergência entre as dimensões do poder soberano, entendido enquanto prática jurídica institucional, e os desdobramentos da micro política, entendida enquanto tecnologias do "eu" e produtoras de subjetividades. 
Todavia Foucault continuou tenazmente até o fim a investigar os "processos de subjetivação" que, na passagem entre o mundo antigo e o moderno, levam o indivíduo a objetivar o próprio eu e a constituir-se como sujeito, vinculando-se, ao mesmo tempo, a um poder de controle externo, e não transferiu suas escavações, como teria sido até mesmo legítimo esperar, ao que poderia apresentar-se como o local por excelência da biopolítica moderna: a política dos grandes Estados totalitários do Novecentos. (AGAMBEN, 2010, p.116)

Foucault (2002, p.44) percebe que o direito soberano não desaparece de cena quando da emergência do biopoder. Ele permanece orientando os códigos judiciários e mantendo a normalização da sociedade: "Um direito da soberania e uma mecânica da disciplina: é entre esses dois limites, creio eu, que se pratica o exercício do poder." No entanto, para Agamben (2010), o biopoder deve ser visto como a "produção original do poder soberano", ou seja, a politização da vida (que Foucault proclama acontecer quando cortaram a cabeça do rei) ocorre no seio do poder soberano, sendo, portanto, anterior ao período moderno.

Para fundamentar sua proposição, Agamben (2010) vai buscar em Aristóteles a distinção grega entre zoé e bios. A primeira entendida enquanto simples fato de estar vivo, ou a qualidade de ser vivente que pode ser estendida a outras espécies de animais. A segunda se refere ao viver na polis, ou seja, uma vida coletiva, política. $\mathrm{O}$ autor identifica que quando se falava em vida (bios) na Grécia antiga, não se pensava na vida natural (zoé) (que ficava restrita a casa (ôikos) como mera dimensão reprodutiva). (Arán \& Peixoto Junior, 2007).

O pensamento aristotélico, quando da definição da comunidade perfeita já fazia a distinção entre o "simples fato de viver" e a vida "politicamente qualificada”. Nesse sentido, na antiguidade, a política já se ocupava da vida dos indivíduos, porém a vida politicamente qualificada era a bios, ao passo que zoé permanecia à margem, fora do ordenamento político. Tratava-se de uma biopolítica baseada na exclusão, na divisão, na definição. Agamben (2010) sustenta que, se a biopolítica é anterior à modernidade, é na modernidade que ela passa a dominar a vida nua. A zoé ascende ao espaço político e se constitui em valor supremo. Se antes a biopolítica era pautada na definição e na exclusão, na modernidade ela será baseada na exclusão/inclusão; direito/fato; interno/ externo; bios/zoé fazendo parte, portanto, de uma zona de indistinção que só pode ser compreendida a partir dos conceitos de estado de exceção e vida nua. (AGAMBEN, 2010) 
Nesse sentido, o autor propõe um estudo com base na organização dos estados totalitários, a fim de investigar a produção dessa zona de indeterminação entre as decisões soberanas e o micro poder; entre o fazer morrer/deixar viver e o fazer viver/deixar morrer.

\section{ESTADO DE EXCEÇÃO E VIDA NUA.}

Tendo em vista o contexto da modernidade, onde a humanidade presenciou a emergência de estados totalitários e o surgimento de dispositivos de poder nunca vistos, como o campo de concentração, Agamben (2004) propõe o estudo acerca das noções de exceção e vida nua para compreender a maneira como o direito, no limiar da modernidade, abarcou a completude da vida humana.

Se antes da modernidade a vida pura, zoé, era deixada à margem do ordenamento político, na modernidade no contexto dos Estados totalitários, a zoé ascende ao centro do espaço político. Essa ascensão é comprovada quando se identificam várias formas legítimas de violência, abandono e extermínio que passaram (e continuam passando) certas parcelas da população. Abordar o dispositivo do estado de exceção permite que Agamben demonstre que o poder soberano materializado nas monarquias absolutistas dos séculos XVII e XVIII permaneceu presente nas democracias liberais do século XIX. Essa presença se pronuncia quando emerge a possibilidade de um poder total, ou seja, o totalitarismo foi gestado no seio das democracias liberais do século XIX. (ROSA, 2007, p. 23) O recurso ao estado de exceção é o que pronuncia a permanência do poder soberano, pois soberano é aquele que decide pelo estado de exceção e pela suspensão da ordem legal. Os detalhes desse debate estão na obra Estado de Exceção, onde Agamben (2004) dialoga com Walter Benjamin e Carl Schmitt. De acordo com Martins (2010) fazendo referencia à Agamben:

Do primeiro ele retoma uma conhecida tese segundo a qual a tradição dos oprimidos nos ensina que o estado de exceção em que vivemos é na verdade regra geral e do segundo ele desdobra o conceito de soberania, onde o filósofo do nazismo afirma que o soberano é aquele que decide sobre o estado de exceção. (Martins, 2010, p. 3)

Buscando as raízes históricas da noção de $e s-$ tado de exceção, Aganbem (2004) vai encontrar nos primórdios da Revolução Francesa o decreto de 08 de julho de 1791 instituindo o estado de sítio. Situado no contexto de formulação jurídica do estado de- 
mocrático, ainda sob os resquícios do absolutismo, a declaração do estado de sítio consistia numa suspensão do regime democrático como forma de proteção do próprio regime democrático, ou ainda como uma decisão extrajurídica como forma de proteção da ordem jurídica. Importa destacar que essa suspensão deveria ser provisória, até que a ameaça externa ou interna à democracia fosse eliminada.

No entanto, Agamben (2004) vai perceber que esse aspecto provisório do estado de sítio vai se tornar, gradualmente, uma técnica de governo. Aplicando a noção de estado de sítio, os alemães desenvolveram a Schutzhaft (literalmente: custódia protetiva):

(...) um estatuto jurídico de derivação prussiana que os juristas nazistas classificaram às vezes como uma medida policial preventiva, na medida em que permitia "tomar sob custódia" certos indivíduos independentemente de qualquer conduta penalmente relevante, unicamente com o fim de evitar perigo para a segurança do Estado. (Agamben, 2010, p.163)

A utilização do estado de exceção era comum nos governos anteriores aos nazistas, chegando a durar cinco meses entre setembro de 1923 a fevereiro de 1924. No entanto é em 28 de fevereiro de 1933 que os nazistas tomaram o poder e suspenderam por tempo indeterminado os artigos da constituição relacionados à liberdade individual. De acordo com o autor, em nenhum ponto da proclamação é citada a palavra estado de exceção, o que, de certa forma, lança o fato dos campos de concentração numa área, ao mesmo tempo, dentro e fora do ordenamento jurídico: "O estado de exceção cessa, assim, de ser referido a uma situação externa e provisória de perigo factício e tende a confundir-se com a própria norma". (Agamben, 2010, p.164)

Nesse sentido o autor vai encaminhar sua análise do estado de exceção não como dispositivo temporário, mas como regra, como técnica de governo: a exceção que vira regra. Essa supressão dos direitos individuais, caracterizado como estado de exceção, mas que no âmbito jurídico não é assumido como medida legal e que, no entanto, é executado como prática de governo prova "a formação de um cenário político como um patamar de indeterminação entre a democracia e o absolutismo". (Martins, 2007, p.4)

É enquanto zona de indeterminação que Aganbem (2010, p. 165) vai situar a formação dos campos de concentração, pois "o campo é o espaço que se abre quando o estado de exceção começa a tornar-se a regra”. É o que se observa quando já em março de 1933, um mês após a tomada do poder, Hitler decide 
criar em Danchau um campo de concentração para prisioneiros políticos, regido por regras exteriores ao direito penal. Essa configuração permite que o autor perceba o campo não como uma anomalia ou como um fato histórico pertencente ao passado, ou ainda como uma lição "aprendida” que nunca se repetirá, mas veja o campo como um espaço político e que mantém fortes relações com o contemporâneo.

Mas como compreender o estatuto da vida "jogada" no campo, totalmente à mercê do poder soberano? Como essa zoé pode se constituir no elemento central do espaço político?

Analisando o campo como paradigma biopolítico do moderno, Agamben (2010) esclarece que a vida se desnuda no campo. Ou seja, é no campo que se observa a vida em seu aspecto mais puro, constituída unicamente em seus aspectos biológicos. Para compreender essa vida nua, o autor se utiliza da figura do Homo Sacer, recorrendo ao direito romano arcaico. Lá constava esse personagem que, quando sentenciado por algum delito, passava a ser sacer (sagrado), ou seja, passava a ter uma vida que não poderia ser sacrificada, por conta de suas culpas. Entretanto aquele que o matasse não seria considerado assassino. Uma vida "insacrificável”, mas "matável”.

Portanto, a vida nua é a vida "matável" do homo sacer. Agamben (2004) esclarece que a questão central não é a sacralidade da vida do homo "sacer”, mas a dupla exclusão a que é submetido: não pertence ao mundo dos deuses nem ao mundo das leis dos homens. Estando situado numa zona de indistinção, sua morte não é sacrifício nem sacrilégio. Nesse sentido, a existência do homo sacer coincide com a existência do campo:

\section{O campo é o espaço em que ordenamento está sus- penso e em seu lugar se coloca a vontade soberana. No campo a vontade soberana coincide com a lei, já que lei é o arbítrio soberano. Nesse caso, a vida humana que cai sob a condição da exceção se torna um verdadeiro homo sacer. É uma vida nua sobre a qual vigora a vontade soberana como lei absoluta e a exceção como norma de sua existência. (RUIZ, 2013, p. 18)}

Assim, Aganbem (2004) comprova a ligação que existe entre homo sacer e soberano, pois a permanência de um confirma o poder do outro. A existência do homo sacer demonstra a fragilidade da vida humana quando abandonada pelo direito, mas também comprova a existência de um poder capaz de suspender a ordem e o direito e decretar a existência da vida nua. É a vida nua do homo sacer que conecta as decisões do poder soberano e as tecnologias empregadas no âmbito do micro poder. 
"fora da lei", mas na condição de "abandonado".

VIDA LOKA, VIDA NUA, BANDIDO, ABANDONADO.

Considerando o homo sacer e o soberano como figuras simétricas, Agamben (2010) avança em sua teoria e articula uma explicação para essa relação com base na noção de bando. A relação de exceção que se estabelece entre soberano e homo sacer se baseia na indeterminação entre interno e externo. Essa indeterminação reproduz a indiscernibilidade do estado de exceção em relação ao direito, pois como pode um estado de suspensão da ordem jurídica estar amparado juridicamente? Ou ainda o soberano que se encontra, ao mesmo tempo, dentro e fora da lei, uma vez que somente ele pode decidir pelo estado de exceção. A noção de bando soberano esclarece essa relação:

(...) in bando, a bandono significam originariamente em italiano ‘à mercê de... ', e bandido significa tanto ‘excluído, banido' quanto ‘aberto a todos, livre'... O bando é propriamente a força, simultaneamente atrativa e repulsiva, que liga os dois pólos da exceção soberana; a vida nua e o poder, o homo sacer e o soberano" (Agamben, 2010, p.117).

Nesse sentido o homo sacer não se encontra
Quando o soberano decreta a vida nua, ele não o faz no sentido de "colocar para fora", mas no sentido de "banir e capturar", "excluir e incluir”, num jogo onde interno e externo se confundem a todo momento. O bandido não é o fora da lei, mas aquele que está situado nessa linha de indeterminação entre vida e direito e, por força dessa posição, relaciona-se diretamente com o poder que o baniu, tornando sua vida mais política que qualquer outra. O paradoxo consiste no fato de o banido, o excluído da comunidade, a vida matável sem valor, constituir-se no espaço privilegiado do político.

O poder soberano depende da produção dessa exceção, pois a dinâmica de refundação do estado, com base no tencionamento com a vida nua, permite a manutenção da ordem, uma vez que o extermínio da vida nua (compreendida como aquela que está fora) transforma o cumprimento da lei em uma dádiva. Não existe pior lugar que o "fora" do ordenamento jurídico.

A vida nua, expulsa da ordem pela exceção da vontade soberana está condenada ao banimento. Ela é uma vida banida e, como consequência, uma vida bandida. A consequência da exceção sobre a vida é o banimento. A vida banida da ordem se torna uma vida bandida. O bando, que também é uma 
figura jurídica do banimento, se transforma socialmente numa vida banida. Os banidos são bandidos porque foram expulsos da ordem e sobre eles se decretou uma exclusão inclusiva que os tornou vida nua. (Ruiz, 2013, p.34)

Cabe destacar que o aspecto central da abordagem empreendida por Aganbem (2004), no que concerne à biopolítica, é a identificação de uma estrutura jurídica, que existe desde a gênese da experiência política ocidental, relacionando direito e vida, ou seja, a existência de um poder soberano e de um estado de exceção que se torna regra na modernidade, capaz de tomar a vida em seu aspecto mais elementar: a nudez da vida sem qualquer direito político, ou um corpo biológico "à mercê" (abandonado) do poder soberano.

Transforma, assim, a totalidade da vida num objeto de gerenciamento do Estado; otimiza as potencialidades vitais e deixa morrer, de acordo com os cálculos de custo benefício estabelecidos pela dinâmica determinante das relações vitais produtivas e de consumo. (Assmann \& Bazzanella, 2012, p. 8)

Outro aspecto que merece destaque é a relação entre exceção e campo, pois uma vez que o Estado, a partir da modernidade, passa a fazer a gerência da vida humana, conferindo-lhe caráter político, a cria- ção de espaços em que a ordem jurídica é suspensa torna-se cada vez mais emblemática. Os campos de concentração do regime nazista são o paradigma, local onde a vida foi despojada integralmente de seus direitos políticos e reduzida à condição de vida nua.

Agamben (2010) sugere que observemos em nossa volta para identificar a estrutura de bando, operada pelo poder soberano e que, contemporaneamente, subsiste de maneira oculta. Reconhecer as ações do estado de exceção e as maneiras como se "captura fora" a vida nua são imprescindíveis para compreensão da biopolítica contemporânea. Mesmo que não existam mais os campos aos moldes do regime nazista, é necessário identificar os espaços em que a ordem jurídica é suspensa prevalecendo uma lógica de exclusão-inclusiva, característica do estado de exceção.

Dessa maneira, o episódio narrado no início desse texto faz todo sentido como manifestação da vida nua "capturada fora" pelo poder soberano. O jovem que foi banido da sua comunidade por ter cometido um delito (roubado uma furadeira) pode ser visto como a vida bandida a que Aganbem (2004) se refere. Ao ser banido pelo poder soberano, que decide por sua morte, (podemos conjecturar que sua saída da comunidade foi uma medida para preservar 
sua vida, uma vez que se permanecesse no grupo poderia ser morto por qualquer um, sem que o autor de sua morte fosse considerado um assassino) o jovem foi desnudado de seus direitos políticos e lançado na condição de homo sacer. Na condição de excluído da ordem, agora se encontra incluído na vida nua. Sua existência vai ser a experiência do limite entre direito e vida. Sua vida foi qualificada (politizada) no momento em que o poder soberano a desqualifica (despolitiza).

Aproximação semelhante pode ser articulada com a noção de vida loka. De acordo com Malvasi (2012), a vida loka pode ser vista como um recurso linguístico (dialeto) que organiza um tipo de experiência comum aos jovens moradores das quebradas.

A utilização do dialeto da vida loka permite: a transferência do proceder e da mente "criminal" para a quebrada - a transferência de atitude e consciência para o crime. A lei das ruas difundidas pelo dialeto vida loka se baseia no reconhecimento de uma experiência comum - a luta cotidiana da vida de jovens que moram nas periferias de SãoPaulo. (Malvasi, 2012, p.145)

O dialeto da vida loka estabelece a compreensão entre a mente criminal com a consciência da periferia, numa espécie de saber que atravessa e orienta as ações dos jovens moradores das periferias urbanas. Interessante destacar que esse dialeto da vida loka ultrapassa os limites daqueles jovens envolvidos com o mundo do crime. De acordo com $\mathrm{Hi}$ rata (2010), o proceder, que conjuga valores como humildade e respeito pode ser observado entre perueiros (transporte ilegal em São Paulo) e outros comerciantes ilegais.

Hirata (2010) observa que a vida loka, analisada a partir das letras de Rap's, particularmente os cantados pelo grupo Racionais Mc's, se apresenta como conceito que sintetiza uma forma de vida marcada pela incerteza, pelo sofrimento moral e pela violência policial:

Este drama cotidiano das vidas precárias, incertas, sempre no limiar entre a vida e a morte, os Racionais chamam de vida loka. E, esta vida loka é o que exige e ativa um certo proceder nas periferias paulistanas. (Hirata, 2010, p. 332)

Esse habitar nas fronteiras entre vida e morte é o que aproxima ou identifica a vida loka com a vida nua, pois, no contexto das periferias brasileiras, o que existe é a incerteza ou uma zona de indeterminação do jurídico. De acordo com Feltran (2010), os moradores das periferias de São Paulo negociam as resoluções de problemas valendo-se da justiça do Estado e da "justiça do crime". Em se tratando 
de problemas oriundos do próprio crime é comum que a justiça seja requerida a alguma autoridade do mundo do crime local.

Essa possibilidade de ser morto pela polícia ou morto pelos seus pares nas atividades do mundo do crime é o que caracteriza a vida nua do vida loka. $\mathrm{O}$ assumir a qualificação de bandido, ou ladrão, desencadeia uma série de desdobramentos que, em última análise, exige uma tomada de decisão "ladrão não fica entre a cruz e a espada; ladrão é ladrão". (Malvasi, 2011, p. 165)

Retomando a noção de homo sacer, percebe-se a consonância com a vida loka dos jovens envolvidos com o crime:

Observemos agora a vida do homo sacer, ou aquelas, em muitos aspectos similares, do bandido, do Friedlos, do acquale et igni interdictus. Ele foi excluído da comunidade religiosa e de toda vida política: não pode participar dos ritos de sua gens, nem (se foi declarado infamis et intestabilis) cumprir qualquer ato jurídico válido. Além disto, visto que qualquer um pode matá-lo sem cometer homicídio, a sua inteira existência é reduzida a uma vida nua, despojada de todo direito, que ele pode somente salvar em uma perpétua fuga ou evadindo-se em um país estrangeiro. Contudo, justamente por ser exposto a todo instante a uma incondicionada ameaça de morte, ele encontra-se em perene relação com o poder que o baniu. Ele é pura zoé, mas a sua zoé é capturada como tal no bando soberano e deve, a cada momento, ajustar contas com este, encontrar o modo de esquivá-lo ou de enganá-lo. Nesse sentido, como sabem os exilados e os banidos, nenhuma vida é mais "política" que a sua (Agamben, 2010, p.178)

\section{CONSIDERAÇÕES FINAIS.}

É incontestável a atualidade e a riqueza com que Agamben trata o debate sobre a biopolítica contemporânea. Pretendi, ao longo desse texto, problematizar alguns conceitos desenvolvidos pelo autor e ensaiar algumas articulações entre a vida nua do homo sacer e a vida loka dos jovens moradores de periferias.

A manifestação do poder soberano se articula no tencionamento entre demandas políticas e jurídicas sobre a vida das pessoas. A existência do poder soberano é comprovada através do mecanismo de inclusão/exclusão da vida e, por conseguinte, produção de vida nua, notadamente pelo dispositivo do estado de exceção, que, como afirma Agamben (2004), deixou de ser excepcional para tornar-se regra na contemporaneidade.

Se no século passado o estado de exceção se materializava no campo de concentração nazista, na contemporaneidade ele se constitui nas bordas dos bairros periféricos das metrópoles. É nesse território 
de ninguém onde o estado de exceção vai se concretizar e a vida nua do homo sacer poderá ser vista em sua natureza.

Exemplo disso são os dados coletados pelo IPEA e apresentados por Cerqueira (2012) relacionando a queda no número de homicídio no Rio de Janeiro com o aumento do número de mortes qualificadas como causa "indeterminada". Argumenta-se que os índices apresentados pelo Estado são questionáveis e que a utilização da truculência policial continua sendo a regra.

Os autos de resistência seguida de morte nas ações policiais somente no ano de 2003 somaram 1.195 casos, sendo que, entre os anos 2003 a 2012 houve 9.646 mortes provocadas por ações policiais no Estado do Rio de Janeiro. (SOARES, 2014) Não se sabe precisar quanto dessas ações efetivamente foram ações extrajudiciais de extermínio, fato que não diminui o peso dos dados, pois se o Estado não consegue investigar as ações da polícia é porque algo de errado vem acontecendo. Uma vez que o poder soberano decide sobre a vida das pessoas e tem autoridade para qualificar ou desqualificar, todos estamos expostos à possibilidade de nos tornarmos vida nua.

Finalmente uma pergunta pode ser formulada no sentido de compreender qual o espaço que poderá ser ocupado pelos sujeitos que se colocarem no contexto desse jogo. Aos que estiverem na condição de vida nua, ou desqualificados dos direitos políticos, caminhando pelos campos de concentração do estado de exceção contemporâneo, o que restará?

Agamben (2010) sugere algumas respostas, dentre elas a que se relaciona ao estado de exceção, que, por ser exceção à regra, pode liberar outros espaços e potencializar diferentes possibilidades de vida, fomentando assim o conflito e articulando novas regras no jogo político. É o que se observa no contexto de vários movimentos culturais e políticos que se articulam em torno da precariedade da vida nas periferias. A identificação da periferia como um campo onde o direito foi suspenso e o estado de exceção produz vida nua oferece a possibilidade do surgimento de contrapontos como o Rap e o dialeto da vida loka.

\section{REFERÊNCIAS BIBLIOGRÁFICAS.}

AGAMBEN, Giorgio. Estado de exceção. São Paulo: Boitempo, 2004.

AGAMBEN, Giorgio. Homo Sacer: o poder soberano e a vida nua. Belo horizonte: UFMG, 2010. 
ARÁN, Márcia \& PEIXOTO JR, Carlos Augusto. "Vulnerabilidade e vida nua: bioética e biopolítica na atualidade". Revista Saúde Pública, vol. 41 n. 5 - outubro, 2007.

ASSMANN, Selvino; Bazzanella, Sandro. "A máquina/dispositivo política: a biopolítica, o Estado de Exceção, a vida nua”. In: LONGUI, Armindo (org.). Fỉlosofia, política e transformação. SP: LiberArs, 2012.

CERQUEIRA, Daniel. Textos para discussão. Ipea, n. 1697, jan, 2012.

DOUGLAS, Mary. Pureza e perigo. São Paulo: Perspectiva, 1976.

FELTRAN, Gabriel de Santis. "Crime e castigo na cidade: os repertórios da justiça e a questão do homicídio na periferia de São Paulo". Cadernos CHR. vol. 23 n.58 - janeiro/abril, 2010.

FOUCAULT, Michel. Em defesa da sociedade. São Paulo: Martins Fontes, 2002.

FOUCAULT, Michel. Vigiar e punir. Petrópolis: Editora Vozes, 2001.

HIRATA, Daniel Veloso. "Sobreviver na adversidade: entre o mercado e a vida". São Paulo: Tese de Doutorado em Sociologia. USP, 2010.

LEITE, Tiago Pereira. "Entre nóias, playboys e a galera da vila : uma etnografia das relações Sociais entre jovens na periferia de Paranaguá - PR". Toledo: Dissertação de Mestrado em Ciências Sociais.

UNIOESTE, 2012.

MALVASI, Paulo Artur. "Entre a frieza, o cálculo e a "vida loka": violência e sofrimento no trajeto de um adolescente em cumprimento de medida socioeducativa”. Saúde Soc. vol.20 n.1 - maio, 2011.

MALVASI, Paulo Artur. "Interfaces da vida loka: um estudo sobre jovens, tráfico de drogas e violência em São Paulo". São Paulo: Tese de Doutorado em Saúde Pública. USP, 2012.

Mano Brown. Vida Loka II. Intérprete: Racionais Mc's. In: Racionais Mc's. Nada como um dia após o outro. São Paulo: Cosa Costra, 2002. 1 cd. Faixa 7. MANSO, Bruno Paes. Crescimento e queda dos homicídios em SP entre 1960 e 2010: Uma análise dos mecanismos da escolha homicida e das carreiras no crime. São Paulo: Tese de Doutorado em Ciências Políticas. USP. 2012.

MARTINS, Jasson da Silva. "Estado de exceção e biopolítica no pensamento de Giorgio Agamben". Revista Tessituras. n. 2 - novembro, 2010.

PEIXOTO JR, Carlos Augusto. "Trauma, vida nua e Estado de Exceção: notas sobre clínica e política". Interações, vol. XI n. 21 - janeiro/junho, 2006.

POGREBINSCHI, Thamy. "Foucault, para além do 
poder disciplinar e do biopoder". Lua Nova, $\mathrm{n}^{0} 63$, 2004.

ROSA, Susel Oliveira da. "Estado de exceção e vida nua: violência policial em Porto Alegre entre os anos de 1960 e 1990. Campinas: Tese de Doutorado em História. UNICAMP, 2007.

RUIZ, Castor Bartolomé. "Homo Sacer: o poder soberano e a vida nua”. Cadernos IHU em formação. Ano. 9 n. 45 - 2013.

RUIZ, Castor Bartolomé. "O campo como paradigma biopolítico moderno". Cadernos IHU em formação. Ano 9 n.45, 2013.

SEQUEIRA, Vania Conselheiro. "Uma vida que não vale nada: prisão e abandono político-social”. Psicologia Ciência e Profissão, vol. 26 n. 4 - dezembro, 2006.

SOARES, Luis Eduardo. Polícia: a sinistra máquina da morte. Outras mídias, 2014. Disponível em http://outraspalavras.net/outrasmidias/destaque-outras-midias/policia-a-sinistra-maquina-da-morte/

SOUZA, Angelita Matos. "Estado de Exceção". Revista Espaço Acadêmico, vol. X n.112 - setembro, 2010. 